\title{
Internacionalização, acessibilidade, popularização e qualidade na RBEFE
}

$\mathrm{O}$ presente número inaugura o volume $27 \mathrm{de}$ 2013 da Revista Brasileira de Educação Física e Esporte - RBEFE. Apesar de ser o número 1, vem precedido pela disponibilização dos artigos "ahead of print", na versão "on line". Cinco artigos foram disponibilizados e veem sendo acessados pelos nossos leitores e pela comunidade em geral, mostrando que o esforço da RBEFE em possibilitar o acesso aos artigos pelo sistema "ahead of print" é uma ação importante, necessária, e apreciada tanto pelos autores, os quais têm seus artigos publicados mais rapidamente, quanto pelos leitores, que buscam novas informações e conhecimento de forma regular e diária. Nesse sentido, a política de aumento da visibilidade e disponibilidade do conteúdo, e ainda, a inserção de notícias sobre a RBEFE e outros assuntos pertinentes à comunidade científico-acadêmica vem merecendo a atenção e aumentando a integração de toda a comunidade, a qual tem acessado a RBEFE através das redes sociais e do nosso Blog com uma elevada frequência e volume substancial de acessos. A RBEFE alinhou as demandas e tendências de popularização da ciência, disponibilização do conhecimento científico, mantendo a qualidade e estimulando a internacionalização. Neste aspecto, é importante ressaltar que nesse número da RBEFE, entre vários artigos de elevada qualidade, contamos com um elegante Ensaio, intitulado "Effects of intensified training and taper on immune function" de autoria de Elena Papacosta e de um dos maiores expoentes da atualidade na área de Imunologia do Exercício, o Prof. Michael Gleeson. Ademais, pesquisadores de diferentes países assinam o artigo "Desempenho coordenativo de crianças: construção de cartas percentílicas baseadas no método LMS de Cole \& Green"; esses artigos ilustram a tendência de internacionalização, necessária para os periódicos brasileiros, porém, não ignorando as particularidades, demandas e impacto social inerentes aos periódicos do Brasil. É pertinente destacar que esse número traz também importantes textos contemplando a pluralidade e diversidade de nossa área, distribuídos entre as seçóes da RBEFE. Finalmente, vale lembrar que o número 1 inaugura a adoção por parte da RBEFE das novas normas de submissão e publicação. Quero agradecer a imensa contribuição de muitos anos da Profa. Kátia Rubio como editora da seção Sociocultural, em meu nome e em nome dos meus antecessores na função de Editor da RBEFE e, ao mesmo tempo, desejar um profícuo trabalho para a Profa. Ana Cristina Zimmermann, que assume esta área na nossa Revista. Meus sinceros agradecimentos a Profa. Kátia Rubio e minhas boas vindas a Profa. Ana Cristina Zimmermann.

Prof. Dr. Alexandre Moreira

Blog da RBEFE - http://rbefe.blogspot.com.br/

Facebook - http://www,facebook.com/reveefe Twitter - https://twitter.com/RBEFE 